\title{
RETRACTED ARTICLE: The expression of mitochondrial complexes I and III correlates with prognosis or diagnosis in retinoblastoma: immunohistochemical and histopathological parameters
}

\author{
Kourosh Shahraki ${ }^{1}$ - Peyman Karimi Goudarzi ${ }^{2} \cdot$ Ali Makateb $^{3} \cdot$ Keyvan Shirzadi $^{3}$. \\ Ebrahim Khodaverdi Darian ${ }^{4} \cdot$ Keivan Khosravifard ${ }^{3} \cdot$ Khosrow Jadidi $^{5}$
}

Published online: 6 November 2015

(C) International Society of Oncology and BioMarkers (ISOBM) 2016

\section{RETRACTED ARTICLE: Tumor Biol.}

DOI 10.1007/s13277-015-4365-3

This article has been retracted at the request of the Editor-inChief, the International Society of Oncology and BioMarkers (ISOBM) and the Publisher per the Committee on Publication Ethics guidelines. The article shows evidence of irregularities in authorship during the submission process, there is strong reason to believe that the peer review process was compromised and the article is showing similarities, which have been paraphrased for a large part, with the following article:

Lata Singha, Neeru Sainib, Sameer Bakhshic, Neelam Pushkerd, Seema Sena, Anjana Sharmae, Jasbir Kaurf,
Seema Kashyapa, Prognostic significance of mitochondrial oxidative phosphorylation complexes: Therapeutic target in the treatment of retinoblastoma. Mitochrondrion. 2015; 23 $55-63$

As such the validity of the content of this article cannot be verified.

The online version of this article contains the full text of the retracted article as electronic supplementary material.
Electronic supplementary material The online version of this article (doi:10.1007/s13277-015-4365-3.) contains supplementary material, which is available to authorized users.

Khosrow Jadidi

kh.jadidi@gmail.com

1 Department of Ophthalmology, Alzahra Eye Hospital, Zahedan University of Medical Sciences, Zahedan, Iran

2 Department of Neurosurgery, AJA University of Medical Sciences, Tehran, Iran

3 Department of Ophthalmology, AJA University of Medical Sciences, Tehran, Iran

4 Young Researchers and Elite Club, North Tehran Branch, Islamic Azad University, Tehran, Iran

5 Department of Ophthalmology, Baqiyatallah University of Medical Sciences, Tehran, Iran 